\title{
Seasonal cycles in food purchases and changes in BMI among South Africans participating in a health promotion programme
}

\author{
Roland Sturm ${ }^{1, *}$, Deepak Patel ${ }^{2}$, Elle Alexander ${ }^{2}$ and Jithen Paramanund ${ }^{2}$ \\ ${ }^{1}$ RAND Corporation, 1776 Main Street, PO Box 2138, Santa Monica, CA 90407-2138, USA: \\ ${ }^{2}$ Vitality/Discovery, Johannesburg, South Africa
}

Submitted 14 September 2015: Final revision received 18 February 2016: Accepted 10 March 2016: First published online 12 May 2016

\begin{abstract}
Objective: Improving diet quality is a key factor for promoting population health. Social norms can support or undermine these efforts. The present study aimed to investigate the relationship between seasonal variation in food purchases and BMI.

Design: The study population comprises members of a South African health promotion programme. Data come from scanner data of food purchases by 400000 enrolled households at supermarkets and repeated individual surveys (about 500000 participants) between 2009 and 2013.

Results: Members in the health promotion programme spent $16.7 \%$ of total food expenditure on nutritionally undesirable foods (sugar-sweetened beverages, candy, ice cream, etc.) and $24.7 \%$ on healthy foods (fruit/vegetables, whole grains, non-fat dairy, etc.). Fruits and vegetables accounted for $13.5 \%$ of purchases (half of all healthy food spending). Yet there were pronounced seasonal variations, with December being the peak month for unhealthy food purchases, which were $40 \%$ higher than in January. This holiday peak was associated with short-term weight gain, but average body mass did not revert to pre-holiday levels. From 2009 to 2013, respondents gained about 0.13 BMI units per year $(0.43 \mathrm{~kg}$ for men, 0.30 for women). From November to January alone, the increase was $0 \cdot 1$ BMI units for men $(0.35 \mathrm{~kg})$ and $0.8 \mathrm{BMI}$ units for women $(0.20 \mathrm{~kg})$.

Conclusions: Purchases of nutritionally undesirable foods peak in December and are accompanied by weight gain from November to January. Despite weight loss after January, the November to January weight gain accounts for $60-70 \%$ of the annual gain.
\end{abstract}

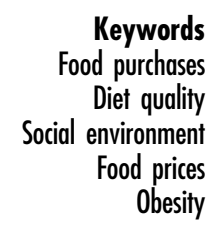

Improving diet quality is a key factor to promoting population health. There is ample evidence that social norms about eating and other people's behaviour have a powerful effect on both food choice and amounts consumed $^{(1,2)}$. Even information about eating norms influences choice and quantity of food eaten ${ }^{(3)}$. Social norms can support or undermine individual intentions and the end-of-year holidays are believed to be a contributor to excess weight gain.

The present study analyses food purchases using supermarket scanner data for about 400000 South African households and individual surveys from about 500000 individuals between 2009 and 2013 to study the relationship between seasonality in food purchases and BMI.

Although conventional wisdom suggests that holiday weight gain is a ubiquitous phenomenon, the public health relevance is not clear because hard evidence is surprisingly sparse and comes primarily from small-scale studies in the USA ${ }^{(4)}$. The most widely cited study had 163 participants, almost all employees of the US National Institutes of Health ${ }^{(5)}$. Average weight gain among adults during the period between mid-November and midJanuary tends to be about $0.5 \mathrm{~kg}^{(5-7)}$. While this is far less than some of the more spectacular claims found in media reports, such a seasonal effect could account for a large proportion of the average annual body weight gain among US adults that has contributed to the 'obesity epidemic $^{\text {,(5) }}$. A recent US study analysed food shopping of 200 households over a period of 7 months $^{(8)}$. It found a $15 \%$ increase in household food expenditure during the November/December period and over July 2010, with $75 \%$ of that increase accounted for by less healthy items ${ }^{(8)}$. In January, sales of healthy foods increased by $30 \%$ compared with the holiday season.

It is unclear whether a similar effect occurs in South Africa, which experiences the southern hemisphere 
summer in December and not winter. Shephard and Aoyagi have postulated that evolutionary responses to shorter days and colder temperatures may be responsible for seasonal weight changes, including a biologically mediated decrease in physical activity to reduce energy expenditure ${ }^{(9)}$. On the other hand, seasonality could be a social phenomenon independent of climate. Documenting increased unhealthy food purchases in South Africa in December, followed by weight gain, would point to social rather than biological reasons for behaviours that are counterproductive to public health in a modern environment.

According to the 2012 South African National Health and Nutrition Examination Survey, $28 \%$ of South Africans were obese and $23 \%$ overweight $^{(10)}$. The rates of obesity were highest among whites and high-income groups. Herein we study a population of South Africans with private health insurance. All study participants are enrolled in a health promotion programme for which they pay an additional monthly fee, but one of the programme benefits is the HealthyFood benefit which offers a rebate of between 10 and $25 \%$ on purchases of healthy foods from a national supermarket chain.

\section{Methods}

\section{Study population and setting}

The study population comprises members of the Discovery Health medical plan who are also enrolled in the supplemental Vitality health promotion programme. Discovery Health is the largest health insurer in South Africa, with about a third of the market, but private health insurance is not common. South Africa has a divided health system, with private voluntary insurance schemes covering about $16 \%$ of the population while the majority of the uninsured receive care in a tax-funded public system ${ }^{(11)}$.

The Vitality health promotion programme provides a HealthyFood benefit that offers a rebate of 10 to $25 \%$ on selected 'healthy' foods ${ }^{(12)}$. During the study period, that rebate was available at approximately 400 supermarkets of the Pick n Pay chain; the number of participating supermarkets has since doubled. The rebate is capped at a maximum monthly purchase amount of R4000 (South African Rand; approximately \$US 480) per household. Although the rebate applies only to some foods, our data include all purchases at the Pick n Pay supermarket chain by Vitality households participating in the HealthyFood programme. The data do not include food purchases at restaurants or other types of stores.

Food items eligible for the rebate programme are based on South African, US and other international dietary guidelines on healthy nutrition and were selected by a panel of nutritionists, physicians and behavioural scientists. Fruits, vegetables, fat-free dairy, lean meats, legumes, unsalted nuts and wholegrain products are included in the list of healthy foods. The complete list of eligible items (over 6000) is available on the insurer's website and distributed as brochures to programme participants.

At the opposite spectrum are foods that are high in saturated fats, trans-fatty acids, added sugar, salt or refined starch. These were classified by the panel as nutritionally undesirable. This 'unhealthy' food group includes sweets, chocolates, ice cream, sugary foods, chips, sugar-sweetened beverages and fried items. Among all shoppers, healthy and unhealthy foods account for roughly $20 \%$ each, but among participants in the HealthyFood benefit the ratio is closer to $25 \%$ healthy and $15 \%$ unhealthy purchases. All foods not specifically classified as 'healthy' or 'less desirable', the majority, are considered neutral and are neither encouraged nor discouraged. 'Neutral' foods on the HealthyFood benefit include white and brown bread, white rice, beef, mutton, pork, full-cream dairy, condiments and seasonings, tinned fruit, vegetables in syrup and salted nuts.

\section{Measures}

Purchases are collapsed into monthly observations, resulting in a total of 7.9 million observations from about 400000 households. This excludes months without any recorded purchases, purchases that do not reflect household consumption (e.g. monthly food purchases over R30 000) and administrative data-entry errors.

Vitality participants are also asked to complete an online survey on health behaviours annually, with completion rates at $17 \%$ of members in 2009 and $27 \%$ of members in 2013. During the study period 2009-2014, Vitality members completed 1.4 million surveys. One dependent variable for the present study is BMI, calculated from self-reported height and weight from the survey. Excluding individuals under 18 or over 75 years of age, missing data on height, weight or extreme values (BMI below 16 or over $60 \mathrm{~kg} / \mathrm{m}^{2}$ ) reduces the number to 1.3 million surveys, completed by about 517000 members. Although there are repeated observations by the same person (on average 2.5 ; the statistical model includes an individual fixed effect to control for this clustering), these data are best viewed as a repeated cross-section with different respondents in each month.

\section{Variable construction}

The main dependent variables for food purchases are the ratios of fruit/vegetables and nutritionally less desirable foods to total food expenditure in a household. The list of healthy foods, other than fruits and vegetables, was modified repeatedly during the study duration and so is not consistently comparable over time; therefore we only show fruit/vegetables and unhealthy items. The absolute amounts per month are adjusted by the consumer price index to correspond to real costs in December $2012^{(13)}$. We report food purchases in South African Rand. To translate them into \$US, the best approximation is purchasing power parity rather than the exchange rate. The purchasing power parity estimated by the Organisation for 
Economic Co-operation and Development for 2012 is 1:5 (i.e. R5 bought as much in South Africa as \$US 1 in the USA).

The dependent variable for individual outcomes is BMI, based on self-reported height and weight from the surveys. There is a well-known tendency towards under-reporting of weight and over-reporting of height, but this appears to be a consistent bias without changes over time ${ }^{(14,15)}$. However, there is no validation specific for this population of South Africans. Self-report has certainly more random error than objective measurement, but this noise averages out with large samples. We have no way to assess whether certain people would be more or less likely to respond to a survey in a particular month or whether the mean bias is different from that in other populations or countries.

\section{Statistical models}

We use descriptive statistics and multiple regression analysis, adjusting standard errors for repeated observations. In regression models, we use a household (for food purchases) and an individual (for BMI) in a fixed-effects method that deals with any selection biases due to a household/individual-specific component (observable or unobservable) as long as it is constant over time. The main explanatory variable is calendar month (capturing seasonality). A linear time trend corrects for a constant trend that is not related to seasonality (highly significant for BMI increase). In individual-level models, age and sex are used as additional control variables. All statistical analyses are conducted in the statistical software package STATA 13. We mention statistical significance only when a comparison is not significant at $P<0.001$ (which in this large sample sizes suggests a more questionable effect). Otherwise, all results are statistically significant at $P<0 \cdot 001$.

Food purchases are long panel data in which the same households appear in consecutive months, while BMI is available in only the survey months (more a repeated cross-section). As a consequence, we do not attempt to merge those two data sets, but analyse them separately.

\section{Etbics statement}

The study uses existing data that were collected as routine business operations. Data had been de-identified prior to use for research purposes. The study was approved by RAND's Institutional Review Board and classified as exempt.

\section{Results}

\section{Food purchases}

Average household purchases from Pick n Pay supermarkets were R1500 per month in the study sample, or about R18000 per year in December 2012 prices. Even though this does not include food purchased for home consumption at other stores nor food away from, it is far higher than the expenditure of the average South African household, which spent approximately R12 200 total on food and non-alcoholic beverages per year according to the 2010/2011 Income and Expenditure Survey ${ }^{(16)}$.

Figure 1 shows the breakdown of food purchases by category. A little over $13 \%$ of food purchases were for fruits and vegetables, with another $9 \%$ for other healthy foods (such as non-fat dairy, lean meats, grains, legumes and nuts). At the other extreme were foods with little nutritional value, such a sugar-sweetened beverages (3\%), chocolates, candy and ice cream. Most food items were classified as neutral.

This average over 5 years obscures a regular seasonal trend. Like a consistent heartbeat, the percentage of food expenditures on nutritionally less desirable foods peaked every December, followed by a drop in January. Figure 2 shows the share of food purchases for unhealthy foods and for fruits/vegetables as a share of total spending.

The holiday effect is even larger in absolute amounts because total food spending was higher in December than in January (by about R80). Absolute amounts were adjusted for the consumer price index in each month and a linear time trend. Purchases of unhealthy food peaked at an average of R312 in December (the highest for the year), compared with R262 in November and R221 in January. Average fruit and vegetable purchases dropped from R219 in November to R206 in December and then increased to R227 in January.

January had the highest spend for fruit and vegetables for the year, although the lowest amount was in June at R182. For unhealthy foods, spending in the highest month (December) was $41 \%$ higher than in the lowest month (January). For fruit and vegetables, the difference between January and June was $20 \%$.

\section{BMI and weight}

The average BMI over the study period was $27 \cdot 2 \mathrm{~kg} / \mathrm{m}^{2}$ for men and $25.4 \mathrm{~kg} / \mathrm{m}^{2}$ for women (without adjusting for age or survey completion date). There was a significant time

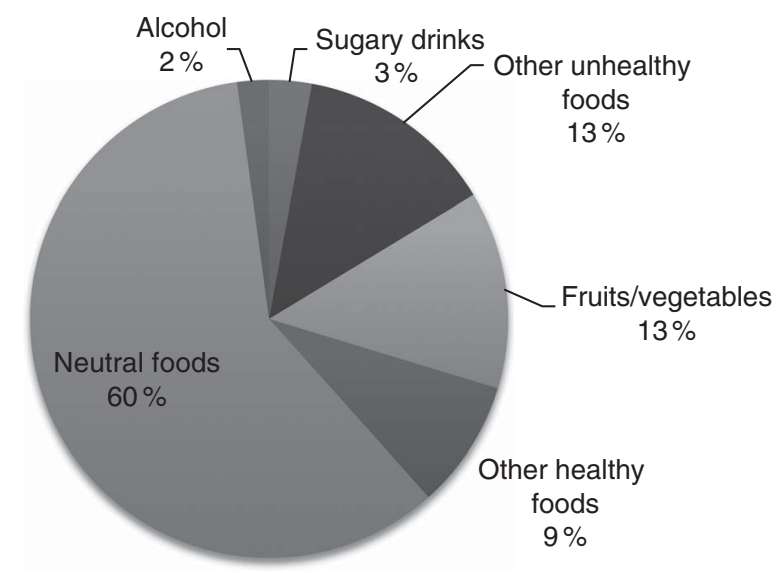

Fig. 1 Percentage of food expenditures by type of food among supermarket purchases by health plan members in South Africa, 2009-2014 


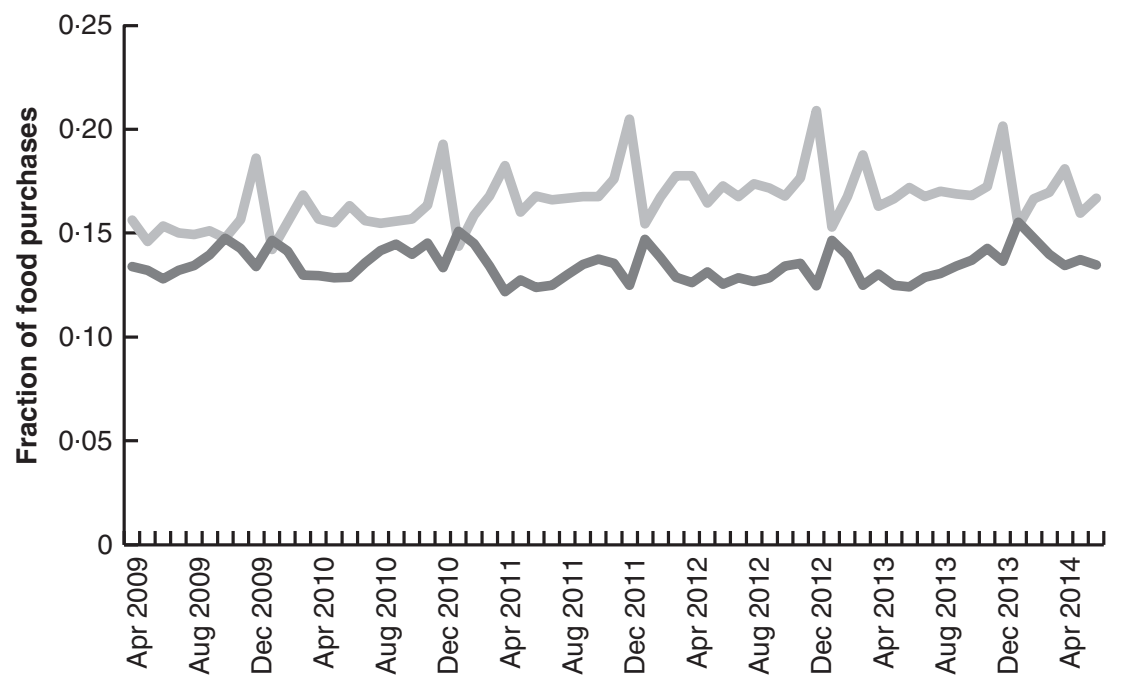

Fig. 2 Share of unhealthy food purchases $\left({ }_{-}\right.$) and fruit/vegetable purchases ( - ) in total food expenditure by month, showing that unhealthy food purchases peak in December, among supermarket purchases by health plan members in South Africa, 2009-2014

Table 1 Seasonality effects in BMI and weight among health plan members in South Africa, 2009-2014

\begin{tabular}{lccccc}
\hline & $\begin{array}{c}\text { Average } \\
\text { annual change }\end{array}$ & SE & $\begin{array}{c}\text { Average difference from } \\
\text { November to following January }\end{array}$ & $\begin{array}{c}\text { Ratio of holiday change } \\
\text { to annual change }\end{array}$ \\
\hline BMl $\left(\mathrm{kg} / \mathrm{m}^{2}\right)$, men & 0.13 & 0.009 & 0.10 & 0.09 & 0.73 \\
BMl $\left(\mathrm{kg} / \mathrm{m}^{2}\right)$, women & 0.13 & 0.01 & 0.08 & 0.01 & 0.60 \\
Weight $(\mathrm{kg})$, men & 0.44 & 0.03 & 0.35 & 0.03 & 0.79 \\
Weight $(\mathrm{kg})$, women & 0.30 & 0.02 & 0.20 & 0.02 & 0.66 \\
\hline
\end{tabular}

Repeated surveys of plan members (264772 women and 252135 men). Self-reported height and weight. Fixed-effects regression including monthly indicator, constant linear time trend, respondent age, age ${ }^{2}$ and sex.

trend, but this increase did not happen consistently over the year. Instead, a very substantial increase appeared to occur from November to January. Table 1 gives a breakdown separately for men and women. The last column gives the ratio of the average November-January change to the average annual change and was calculated using more precise regression coefficients rather than the rounded values in columns 2 and 4. Men appeared to gain a higher share of total excess weight in the holiday season than women, although this is not a main finding. There were similar, but not identical, changes for weight and BMI (last column), which could be a consequence of other changes in the population due to enrolment/disenrolment that changes the height distribution as well or an indication of the noise inherent in the data.

\section{Discussion}

The present paper provides new data on the topic of seasonal changes in eating behaviour and weight - the first, we believe, for South Africa. Small annual weight gains, well under $1 \mathrm{~kg}$, have contributed to the high rates of overweight and obesity worldwide, yet these gains may be concentrated at particular time points. The most widely cited papers suggest that holiday weight gain in the USA is responsible for half of the annual weight gain ${ }^{(5)}$. We confirm a similar result for South Africa. This is a notable finding given the opposite climate pattern (summer, rather than winter as in the northern hemisphere), which points to the importance of the social environment rather than evolutionary responses to shorter days and colder temperatures to increase stored energy.

This weight gain is preceded by increased food purchases from supermarkets, in particular disproportionate increases in purchases of foods that a panel of scientists has classified as nutritionally less desirable. Understanding and possibly changing the social norms defining eating and food purchasing patterns over the holidays is important. We observe a reversal in food purchases in January, compared with December: fruit and vegetable purchases are highest and unhealthy food purchases are lowest in January. This could reflect a 'New Year's resolution' to begin a healthy year, but such inconsistent diet behaviours tend to be predictors of weight gain ${ }^{(17)}$. One recent US study reported higher-energy purchases to continue past the holidays, but with a sample of 200 households observed for a single season, this may not be a generalizable finding ${ }^{(8)}$.

Robust norms about food consumption were shaped by many centuries of food shortages. While each culture has 
elaborate norms about food and eating behaviours, norms about reciprocity sharing of food seem to be pervasive ${ }^{(18)}$. There are universal expectations that guests should be offered food, ample food even, especially sweet and rich foods that were historically scarce. 'Pushing food' is a sign of a good host and declining the offer of food is often considered socially inappropriate behaviour ${ }^{(19)}$. Yet such norms may be maladaptive in an economic environment where food availability is no longer constrained. As the worldwide obesity epidemic shows, no society has yet developed social norms that deal with excessive food intake.

Many policy interventions are focusing on 'positive' approaches or messages, such as increasing fruit and vegetable consumption and increasing physical activity. But an emphasis on reducing consumption of discretionary kilojoules, particularly sugar-sweetened sodas and salted snacks, may be a promising lever to reduce overweight and obesity. The majority of adults exceed the amount of recommended discretionary kilojoules for energy balance. While increasing fruit and vegetable consumption may be a laudable goal for other health reasons, it is unlikely to be an effective tool for obesity prevention $^{(20)}$. Overall energy intake must be appropriate for weight maintenance and reduced for weight loss.

Pope and colleagues ${ }^{(8)}$ propose several strategies that may be useful in controlling the increased food purchasing impulses during the US holiday season, but these suggestions are just as applicable to South Africa. Predetermined shopping lists may deter impulsive purchasing at the grocery store. Stepped-up advertisements and promotions of soft drinks, candy and chocolates not only lead to impulse purchases, but such advertisements and promotions also change perceptions about what is normal and expected; even just information about others' eating norms influences food choices ${ }^{(3)}$. Helping shoppers remember their purchasing patterns might be a good way to help prevent December excesses. Visual cues that divide shopping carts and baskets in half and encourage the consumer to fill half the cart with high-nutrient items may be one way to increase consumption of healthier foods, while simultaneously restricting the number of 'junk food' items purchased.

There are multiple limitations to our analysis, making this a first data point for South Africa rather than a determination that holidays are behind South Africa's obesity epidemic. Our focus is on seasonal effects among shoppers at one supermarket chain; we have nothing to say about long-term trends in food supply, relative prices, or cross-sectional differences between sociodemographic groups (food deserts, disparities). We relied on selfreported measures of height and weight, which essentially amount to repeated cross-sections. Measurement errors on those variables are likely to be smaller among participants in a health promotion programme than in a general population, but random reporting errors are not a problem with large samples, nor are the well-known self-response biases as long as they remain constant. However, if January respondents were systematically different (e.g. responding in January because of perceived weight gain), it would affect the conclusion and we have no way to test this. Food purchases are objectively measured, but only at participating stores and we have no data on meals bought at restaurants or at competing stores. The biggest limitation on food purchases is that only expenditures are available; the data are not linkable to quantities and nutrition information (kilojoules or nutrients). Unit price changes, especially holiday discounts that are very common, could affect kilojoules differently from purchase amounts, most likely in the direction of exacerbating the effects we see.

The study population is not representative for South Africa in several ways, including much higher average income. Most importantly, they were all members in a voluntary health promotion programme for which they paid an additional monthly fee. We expect that this population is far more aware of its health habits than the average population in virtually any country and less vulnerable to marketing of unhealthy foods. This group spends a larger share of its food budget on healthy items than other South African households with private health insurance $^{(12)}$. Yet we see a pronounced increase in unhealthy food purchases during December and an annual peak in BMI even in this population.

\section{Conclusion}

The current analysis finds that unhealthy food spending is highest in December, followed by a reversal in January. The holiday season appears to lead to weight gain that accounts for much of the annual weight gain and is not completely offset by weight loss after January. These findings support the need for increased focus on interventions to address health habits during holidays, when there appears to be a significant disruption in dietary behaviour that may lead to disproportionate weight gain. Successful interventions to improve diets during the holidays may be one component in the prevention of obesity.

\section{Acknowledgements}

Acknowledgements: Cindy Mtsweni provided programming assistance with data. Financial support: This project was funded by Vitality/Discovery. The funder had no role in the design, analysis or writing of this article. Conflict of interest: None. Authorship: R.S. formulated the research question and analysed the data; all authors contributed to writing the paper and approved the final version. Ethics of buman subject participation: The study used existing data that were collected as routine business operations. Data had been de-identified prior to use for research purposes. 
The study was approved by RAND's Institutional Review Board and classified as exempt.

\section{References}

1. Higgs S (2015) Social norms and their influence on eating behaviours. Appetite 86, 38-44.

2. Cruwys T, Bevelander KE \& Hermans RC (2015) Social modeling of eating: a review of when and why social influence affects food intake and choice. Appetite 86, 3-18.

3. Robinson E, Thomas J, Aveyard P et al. (2014) What everyone else is eating: a systematic review and meta-analysis of the effect of informational eating norms on eating behavior. J Acad Nutr Diet 114, 414-429.

4. Schoeller DA (2014) The effect of holiday weight gain on body weight. Physiol Behav 134, 66-69.

5. Yanovski JA, Yanovski SZ, Sovik KN et al. (2000) A prospective study of holiday weight gain. $N$ Engl J Med 342, 861-867.

6. Stevenson JL, Krishnan S, Stoner MA et al. (2013) Effects of exercise during the holiday season on changes in body weight, body composition and blood pressure. Eur J Clin Nutr 67, 944-949.

7. Hull HR, Radley D, Dinger MK et al. (2006) The effect of the Thanksgiving holiday on weight gain. Nutr J 5, 29.

8. Pope L, Hanks AS, Just DR et al. (2014) New Year's res-illusions: food shopping in the new year competes with healthy intentions. PLoS One 9, e110561.

9. Shephard RJ \& Aoyagi Y (2009) Seasonal variations in physical activity and implications for human health. Eur $J$ Appl Physiol 107, 251-271.

10. Mchiza ZJ, Parker WA, Makoae M et al. (2015) Body image and weight control in South Africans 15 years or older: SANHANES-1. BMC Public Health 15, 992.
11. McIntyre D \& Ataguba JE (2012) Modelling the affordability and distributional implications of future health care financing options in South Africa. Health Policy Plan 27, Suppl. 1, i101-i112.

12. Sturm R, An R, Segal D et al. (2013) A cash-back rebate program for healthy food purchases in South Africa: results from scanner data. Am J Prev Med 44, $567-572$.

13. Statistics South Africa (2015) CPI Headline. http://www. statssa.gov.za/publications/P0141/CPIHistory.pdf (accessed January 2016).

14. Stunkard AJ \& Albaum JM (1981) The accuracy of selfreported weights. Am J Clin Nutr 34, 1593-1599.

15. Hattori A \& Sturm R (2013) The obesity epidemic and changes in self-report biases in BMI. Obesity (Silver Spring) 21, 856-860.

16. Statistics South Africa (2012) Income and Expenditure of Households 2010/2011. http://www.statssa.gov.za/ publications/P0100/P01002011.pdf (accessed January 2016).

17. Gorin AA, Phelan S, Wing RR et al. (2004) Promoting longterm weight control: does dieting consistency matter? Int J Obes Relat Metab Disord 28, 278-281.

18. Gurven M \& Jaeggi AV (2015) Food sharing. In Emerging Trends in the Social and Behavioral Sciences: An Interdisciplinary, Searchable, and Linkable Resource [R Scott and S Kosslyn, editors]. John Wiley \& Sons, Inc.; available at http://onlinelibrary.wiley.com/doi/10.1002/9781118900772. etrds0133/abstract (accessed March 2016).

19. Fieldhouse P (1995) Social functions of food. In Food and Nutrition: Customs and Culture, pp. 78-105. New York: Springer.

20. Cohen DA, Sturm R, Scott M et al. (2010) Not enough fruit and vegetables or too many cookies, candies, salty snacks, and soft drinks? Public Health Rep 125, 88-95. 